\title{
Climate change impact on soil salt accumulation in Khon Kaen, Northeast Thailand
}

\author{
Koshi Yoshida ${ }^{1}$, Supranee Sritumboon ${ }^{2}$, Mallika Srisutham ${ }^{3}$, Koki Homma ${ }^{4}$, \\ Masayasu Maki ${ }^{5}$ and Kazuo Oki ${ }^{6,7}$ \\ ${ }^{1}$ Graduate School of Frontier Sciences, The University of Tokyo, Japan \\ ${ }^{2}$ Regional Office 5, Land Development Department, Thailand \\ ${ }^{3}$ Faculty of Agriculture, Khon Kaen University, Thailand \\ ${ }^{4}$ Graduate School of Agricultural Science, Tohoku University, Japan \\ ${ }^{5}$ Faculty of Food and Agricultural Sciences, Fukushima University, Japan \\ ${ }^{6}$ Faculty of Engineering, Kyoto University of Advanced Sciences, Japan \\ ${ }^{7}$ Institute of Industrial Science, The University of Tokyo, Japan
}

\begin{abstract}
:
In northeast Thailand, $17 \%$ of the total agricultural land is classified as salt-affected. In the future, climate change may exacerbate salt-affected soil problems. Therefore, in this study, we conducted a field survey to evaluate seasonal changes in soil electrical conductivity (ECe) in salt-affected paddy areas of Ban Phai District, Khon Kaen Province, northeast Thailand. Fifteen soil samples were collected every 2 weeks from October 2016 to December 2018, and the ECe, soil water content, and soil textures were analyzed. Then, the HYDRUS-1D model was applied to estimate seasonal changes in the salinity level, and the simulated results corresponded well with observed data. Using HYDRUS-1D and the global circulation model (MIROC5) outputs under the Representative Concentration Pathways 8.5 scenario, future ECe was predicted. Under a temperature increase of $2.8^{\circ} \mathrm{C}$ from 2016 to 2100 , annual potential evapotranspiration increased from 1,430 mm (2016-2025) to $1,584 \mathrm{~mm}(2081-2100)$. The average ECe in cultivation season increased from $2.63 \mathrm{dS} / \mathrm{m} \quad(2016-2025)$ to $3.31 \mathrm{dS} / \mathrm{m}$ (2081-2100). As a countermeasure to mitigate soil salt accumulation, a $5 \mathrm{~cm}$ reduction in groundwater level offsets the negative impact of climate change, and a $10 \mathrm{~cm}$ reduction significantly improves the soil ECe relative to the current soil salinity level.
\end{abstract}

KEYWORDS salt affected soil; paddy rice; HYDRUS-1D; climate change; Thailand

\section{INTRODUCTION}

Soil salt accumulation is a major soil degradation process that threatens ecosystems and is the critical global problem for agricultural production. Soil salinization occurs under almost all climatic conditions; however, the problem is more severe in arid and semi-arid regions than in humid regions (Hassani et al., 2020). Salinity decreases the capac- ity of plants to uptake water thereby reducing agricultural productivity (Oo et al., 2011). In addition, when surface plants die and the soil becomes bare, salt crusts (a thin layer of dense salt near the soil surface) are formed, and the physical properties of the soil deteriorate (Parihar et al., 2015). Soil salinity levels change spatially, vertically, and temporally, particularly within the topsoil layer $(0-30 \mathrm{~cm})$, which is easily affected by climatic conditions (Hassani et al., 2020). Recently, the impact of climate change on soil salinization has attracted research attention (Mukhopadhyay et al., 2021). The rise in greenhouse gas (GHG) concentrations and the consequent increases in air temperature or decreases in rainfall are driving forces with possibly huge impacts on soil salinization (Haj-Amor and Bouri, 2020). Therefore, monitoring and assessing the impacts of climate change on soil salinity is crucial for predicting future trends and designing irrigation and crop management practices that will maintain the agricultural productivity of affected areas (Corwin and Scudiero, 2020).

Thailand, among many countries, faces the problem of soil salinization. Although salt-affected soils can be found in coastal and inland areas throughout Thailand, the most affected area is the northeastern region (Arunin and Pongwichian, 2015). Northeast Thailand covers approximately $1 / 3$ of the kingdom in both area and population, and over $70 \%$ of its population is engaged in rainfed agriculture. The major constraints on agriculture include water shortages, low fertility, and soil salinity. The source of salt in the northeast is halite from the Maha Sarakham Formation (Dissataporn et al., 2002), which underlies approximately $30 \%$ of the area. Deforestation in the 20th century has been the main cause of uplifting the groundwater table and soluble salts moving from the lower strata to the soil surface (Miura and Subhasaram, 1990; Sahunalu, 2003). The improvement of the salt-affected soils in Northeast Thailand is a major concern of the responsible agency, the Land Development Department (LDD), and other relevant institutions.

The electrical conductivity of a saturated soil extract
Correspondence to: Koshi Yoshida, Graduate School of Frontier Sciences, The University of Tokyo, 5-1-5 Kashiwanoha, Kashiwa, Chiba 277-8563, Japan. E-mail: kyoshida@edu.k.u-tokyo.ac.jp
Received 17 August, 2021

Accepted 13 September, 2021 Published online 26 November, 2021

(C) The Author(s) 2021. This article is distributed under the terms of the Creative Commons Attribution 4.0 International License (http://creativecommons.org/ licenses/by/4.0/), which permits unrestricted use, distribution, and reproduction in any medium, provided you give appropriate credit to the original author(s) and the source, provide a link to the Creative Commons license, and indicate if changes were made. 
(ECe) is the most useful and reliable measure of salinity for comparing between soil types, as it accounts for water holding capacity in different soil texture, and it reflects the suitability of the soil for growing crops. However, this method requires conventional soil sampling and laboratory analyses, an expensive and time-consuming process. Numerical models have the advantage of reducing the necessary monitoring frequency and cost. HYDRUS-1D is one of the most widely used models for solving soil-related problems (Merdun, 2012). The features of HYDRUS-1D that are advantageous for this study include the option to model the coupled transport of water and solutes in the soil. HYDRUS-1D can also calculate runoff, evaporation, and infiltration fluxes at the soil surface and drainage fluxes through the bottom of the soil profile (Simunek et al., 2016). Several studies have been conducted to validate the model's accuracy in predicting water and salt transport in semi-arid and arid regions by comparing measured values with those calculated using HYDRUS-1D. Ramos et al. (2011) performed a long-term simulation of salinity and nitrogen in soil and reported that HYDRUS-1D is a powerful tool for analyzing various solute concentrations. Kanzari et al. (2018) simulated the water balance and salt transport in a semi-arid region of Tunisia using HYDRUS-1D and found it to be reliable. Li et al. (2015) applied HYDRUS-1D to the dynamics of water and salt in an arid wetland in China and revealed high accuracy. However, few studies have been conducted in Thailand, where salt accumulation remains a serious problem.

Therefore, this study aimed to identify salt accumulation risks, in response to climate change, in northeast Thailand through long-term simulations using HYDRUS-1D. To evaluate seasonal changes in soil ECe, 15 soil samples were collected every 2 weeks from October 2016 to December 2018, and the ECe, soil water content (SWC), and soil textures were analyzed. The model parameters of HYDRUS-1D were calibrated and validated by comparison with observed data. Then, using the model, future soil salinity levels were predicted, and the effect of groundwater control was assessed as a countermeasure for climate change adaptation.

\section{METHODS}

\section{Study area}

The study area was located in the salt-affected area of Ban Phai District, Khon Kaen Province, northeast Thailand (Figure 1). LDD classifies agricultural land into four classes according to the degree of salt affect: class 1 "very severely" (salt crust $>50 \%$ ), class 2 "severely" (salt crust 10-50\%), class 3 "moderately" (salt crust 1-10\%), and class 4 "slightly" (salt crust $<1 \%$ ) (Roengsak and Somsak, 2012). Soil salinity is a measure of the concentration of all soluble salts in soil water and is typically expressed by the ECe in saturated paste. Seasonal change in ECe is an important factor in the design of the cropping system because the threshold for rice yield reduction is $3 \mathrm{dS} / \mathrm{m}$ of ECe, with 90 percent yield loss at $10 \mathrm{dS} / \mathrm{m}$ (Food and Agriculture Organization, 2012). In this study, a class 2 field located at $16^{\circ} 03.4^{\prime} \mathrm{N}, 102^{\circ} 40.2^{\prime} \mathrm{E}$ was selected, and 15 soil samples were collected from the $0-15 \mathrm{~cm}$ soil layer every 2

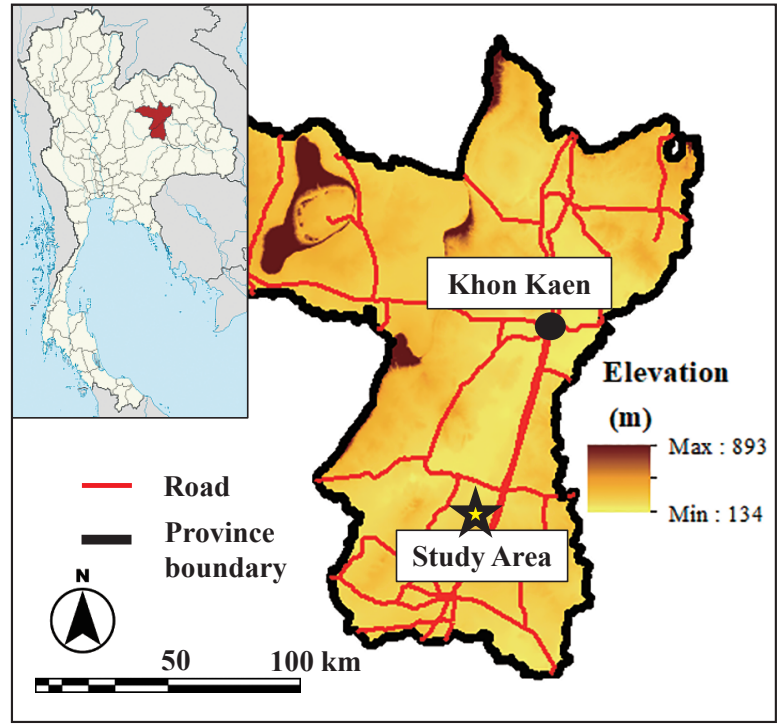

Figure 1. Study area in Khon Kaen province, Thailand

weeks from October 2016 to December 2018. Currently, farmers can cultivate rice paddies in class 2 fields under rainfed condition using salt-tolerant varieties, like Khao Dawk Mali 105 (KDML105) (Arunin and Pongwichian, 2015); however, no crop can grow in class 1 fields. Therefore, protecting class 2 fields is a major concern for sustainable agriculture in this area. The ECe, SWC, and soil textures were analyzed at the laboratory of the LDD Regional Office 5. To measure the soil ECe, deionized water was added to soil samples until saturation, and soil water was suctioned by vacuum pump after being left for 24 hours, then the EC value of the extracted water was measured by EC meter. Meteorological data such as rainfall, solar radiation, wind speed, air temperature, and humidity were also monitored, and potential evapotranspiration (ET) was estimated using the Penman-Monteith equation (Allen et al., 1998). Figure 2 a shows the daily observed precipitation, potential evapotranspiration (PET) and air temperature (Ta) and Figure $2 \mathrm{~b}$ shows daily measurements for the groundwater level from soil surface and groundwater EC. Annual rainfall was $1336 \mathrm{~mm}$ in 2017 and $1259 \mathrm{~mm}$ in 2018, and the air temperature varied in the range of $16.0^{\circ} \mathrm{C}$ to $33.2^{\circ} \mathrm{C}$. The groundwater level (GWL) varied in the range of $-30.6 \mathrm{~cm}$ on Sep. 1, 2017 to $-209.0 \mathrm{~cm}$ on Apr. 6, 2018 from the soil surface, and its EC varied in the range of $39.6 \mathrm{dS} / \mathrm{m}$ to $47.5 \mathrm{dS} / \mathrm{m}$, respectively. In soil sample measurements, estimating representative values at the target site is difficult owing to high non-uniformity. Phontusang et al. (2018) also reported the spatial heterogeneity of soil ECe in this region, and in such a case, Yavitt et al. (2009) identified boxplots as useful for recognizing outliers. Under the conditions of high heterogeneity, the use of a median value, independent of outliers, is recommended (Dołęgowska et al., 2016). Therefore, in this study, the median value was employed when analyzing the correlations between precipitation, SWC, and soil ECe. The soil texture in the study area is loam or sandy loam with a sand content of $36 \%$ $72 \%$, silt content of $22 \%-47 \%$, and clay content of $6 \%$ $22 \%$. 

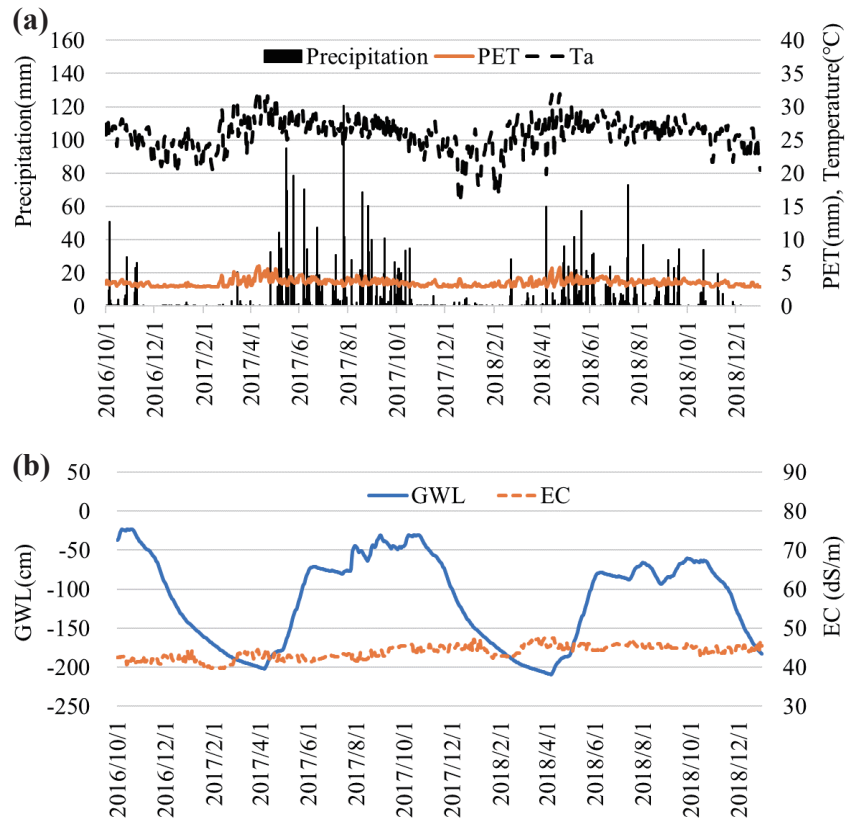

Figure 2. Daily observed data in class 2 field (2006/Oct2018/Dec), (a) precipitation, potential evapotranspiration and air temperature, (b) groundwater level and EC

\section{HYDRUS-1D}

HYDRUS-1D simulates the one-dimensional movement of water, heat, and multiple solutes in unsaturated, partially saturated, or fully saturated porous media (Simunek et al., 2016). The flow and transport domains may be nonuniform or layered soils. Physical non-equilibrium solute transport is considered by assuming a dual-porosity approach, in which the total soil porosity is partitioned into two regions: mobile and immobile.

The mathematical expression of Richards equation for water flow is as follows:

$$
\frac{\partial \theta}{\partial t}=\frac{\partial}{\partial z}\left[K(h) \frac{\partial h}{\partial z}-K(h)\right]
$$

where $\theta$ is the volumetric SWC, $t$ is the time, $h$ is the soil water pressure, $z$ is the vertical coordinate, and $K(h)$ is the unsaturated hydraulic conductivity as a function of $h$. The unsaturated soil hydraulic properties were described using the van Genuchten-Mualem function.

$$
\begin{aligned}
& K(h)=K s \cdot S e^{l} \cdot\left[1-\left(1-S e^{1 / m}\right)^{m}\right]^{2} \\
& S e(h)=\frac{\theta(h)-\theta r}{\theta s-\theta r}=\left(1+\alpha \cdot|h|^{n}\right)^{-m}
\end{aligned}
$$

where $S e$ is the effective saturation, and $\theta r$ and $\theta s$ are the residual and saturated SWC, respectively. $K s$ is the saturated hydraulic conductivity, $\alpha$ and $n$ represent the empirical shape parameters, $m=1-1 / n$, and $l$ is the pore connectivity parameter.

The advection-dispersion equation governs the solute transport in a variably saturated soil:

$$
\frac{\partial(\theta \cdot c)}{\partial t}=\frac{\partial}{\partial z}\left[\theta \cdot D \cdot \frac{\partial c}{\partial z}-v \cdot \theta \cdot c\right]
$$

where $c$ is the solute concentration of the liquid phase, $D$ is the dispersion coefficient, and $v$ is the average pore water velocity.

In Hydrus-1D, EC is expressed as the electrical conductivity of the soil solution $(E C w)$. Therefore, the simulated $E C w$ is converted into $E C e$ by the following relation $(\mathrm{Li}$ et al., 2015):

$$
E C e=E C w \cdot \frac{\theta}{\theta_{s}}
$$

where $\theta s$ is the saturated soil water content.

The upper surface of the soil profile corresponds to the atmospheric boundary condition with a surface layer, where the rainfall and potential evapotranspiration estimated from the climate data are specified, and the bottom boundary condition is set to the flux boundary based on groundwater level. For the solute transport, the upper boundary conditions correspond to the type of concentration flux boundary, and the bottom boundary condition is set as the concentration boundary based on the observed EC of groundwater in Figure 2b.

\section{Simulation scenarios}

To understand the impacts of future climate change on salt accumulation risk, future SWC and ECe values were calculated using the global circulation model projections. We used the future prediction data of the Model for Interdisciplinary Research on Climate (MIROC5), developed jointly at the Center for Climate System Research (CCSR), University of Tokyo, National Institute for Environmental Studies (NIES), and Japan Agency for Marine-Earth Science and Technology. In this study, we employed basic bias correction method which modifies the daily variability of the simulated data about their monthly means to match the observed daily variability (Hempel et al., 2013). Data from the 2006 to 2017 historical run were used for bias correction against observed data at Khon Kaen station, whereas data from the 2041-2060 and 2081-2100 runs were used to assess future risk under Representative Concentration Pathways (RCP) 8.5, generally considered the worst-case scenario. The model predicts that the air temperature will increase by approximately $2.8^{\circ} \mathrm{C}$ during $2016-2100$, whereas the annual rainfall, radiation and non-rainy days will not change significantly.

\section{RESULTS AND DISCUSSION}

In HYDRUS-1D, inverse parameter estimation is available, which is a gradient-based, local optimization approach based on the Marquardt-Levenberg method (Simunek et al., 2016). In this study, inverse solutions were applied to optimize 8 parameters of the soil hydraulic and solute transport in Table I (except the sand, silt clay context) simultaneously using the observed data and boundary conditions. The correspondence between the predicted and observed data was evaluated using the root mean square error (RMSE). 


$$
\mathrm{RMSE}=\sqrt{\frac{\sum_{i=1}^{N}\left(O_{i}-P_{i}\right)^{2}}{N}}
$$

where $O$ are the observed or measured values, $P$ are the model prediction or estimation values, and $N$ is the number of observations.

Table I shows the optimized parameters by inverse solutions, and Figures $3 \mathrm{a}$ and $3 \mathrm{~b}$ show the daily basis output of seasonal changes in SWC and ECe, respectively. Calibration and verification periods were set as Oct 2016-Oct 2017 and Nov 2017-Dec 2018, respectively. The estimated RMSE of SWC was $0.028 \mathrm{~cm}^{3} / \mathrm{cm}^{3}$ for calibration and $0.031 \mathrm{~cm}^{3} / \mathrm{cm}^{3}$ for the verification period. The estimated

Table I. Used parameter values

\begin{tabular}{cc}
\hline Sand (\%) & 47.7 \\
Silt (\%) & 37.5 \\
Clay (\%) & 14.8 \\
Bulk density & 1.5 \\
$\theta \mathrm{r}$ & 0.022 \\
$\theta \mathrm{s}$ & 0.227 \\
$\mathrm{n}$ & 1.4 \\
$\mathrm{Ks}$ & 15.8 \\
$\mathrm{l}$ & 1.26 \\
$\mathrm{D}$ & 32.9 \\
\hline
\end{tabular}
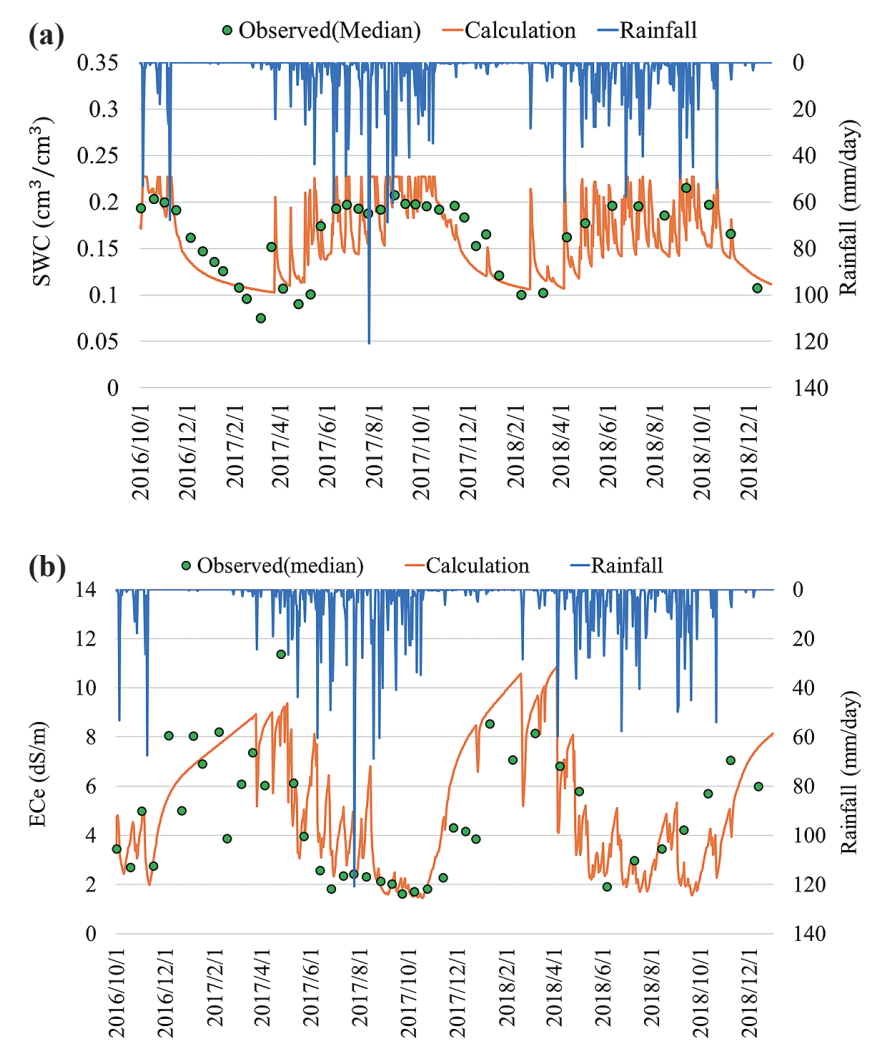

Figure 3. Comparison of observed and calculated daily (a) soil water content and (b) soil ECe (2016/Oct-2018/Dec)
RMSE of soil ECe was $1.72 \mathrm{dS} / \mathrm{m}$ for calibration and $2.19 \mathrm{dS} / \mathrm{m}$ for the verification period. When ECe was converted to $\mathrm{ECw}$, the estimated RMSE of soil ECw was $0.10 \mathrm{dS} / \mathrm{m}$ for calibration and $0.13 \mathrm{dS} / \mathrm{m}$ for the verification period. In a previous study using HYDRUS-1D to simulate salinity dynamics, Ramos et al. (2011) performed a simulation of salinity in a soil irrigated with saline water in southern Portugal and reported that calculated water content (RMSE: $0.04 \mathrm{~cm}^{3} / \mathrm{cm}^{3}$ ), and ECw of the soil solution (RMSE: $0.99 \mathrm{dS} / \mathrm{m}$ ) were in good correspondence with the measured values. Kanzari et al. (2018) simulated the water balance and salt transport in a semi-arid region of Tunisia using HYDRUS-1D and found it to be reliable (RMSE: SWC $0.10 \mathrm{~cm}^{3} / \mathrm{cm}^{3}$, ECW $0.10 \mathrm{dS} / \mathrm{m}$ ). Li et al. (2015) modeled water and salt dynamics in an arid wetland in China and observed that the accuracy of HYDRUS was high (RMSE: SWC $0.031 \mathrm{~cm}^{3} / \mathrm{cm}^{3}$, ECw $0.037 \mathrm{dS} / \mathrm{m}$ ). HajAmor and Bouri (2020) obtained an RMSE with a range of $0.11-0.23 \mathrm{dS} / \mathrm{m}$ for soil $\mathrm{ECW}$ and a range of $0.011-$ $0.021 \mathrm{~cm}^{3} / \mathrm{cm}^{3}$ for SWC. Compared with these previous studies, the RMSE of both SWC and soil ECe in this study were satisfactorily accurate.

Figure 4 shows the seasonal change of soil ECe during 2041-2060 and 2081-2100, together with the current baseline ECe during 2016-2025. Future ECe increments were relatively large in the dry season (Nov-Apr). However, ECe change in rainy season is more important in this area because rice cultivation season is in the rainy season (MayOct) under rainfed condition. The threshold for rice yield reduction is $3 \mathrm{dS} / \mathrm{m}$ of ECe, therefore suitable cultivation periods become shorter especially in 2081-2100 and it also affects the crop calendar.

Figure 5 shows the box plot of the estimated future ECe in the rice cultivation season (May-Oct) during 2041-2060 and 2081-2100, together with the current baseline ECe during 2016-2025. Due to the temperature increase of $2.8^{\circ} \mathrm{C}$ from 2016 to 2100 , annual potential evapotranspiration increased from $1,430 \mathrm{~mm}(2016-2025)$ to $1,584 \mathrm{~mm}$ (2081-2100). The predicted ECe in cultivation season increased significantly, by $25.7 \%$, at a rate of $0.01 \mathrm{dS} / \mathrm{m} /$ year in the period 2016-2100. This is relatively low compared to previous studies because of the relatively larger rainfall. Phogat et al. (2018) evaluated future salinity risks to viticulture in South Australia by running the HYDRUS-1D model using the GCM (GFDL ESM2 M) data downscaled for RCP8.5. They reported that ECw

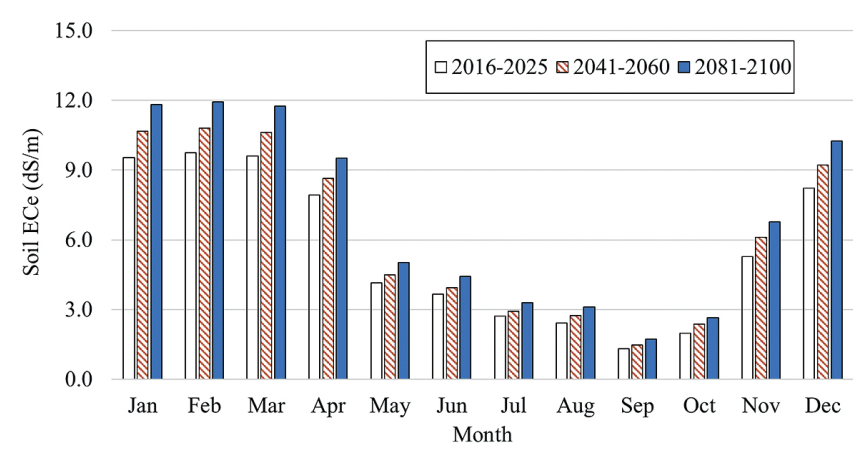

Figure 4. Seasonal change of Soil ECe under climate change condition (2016-2100) 


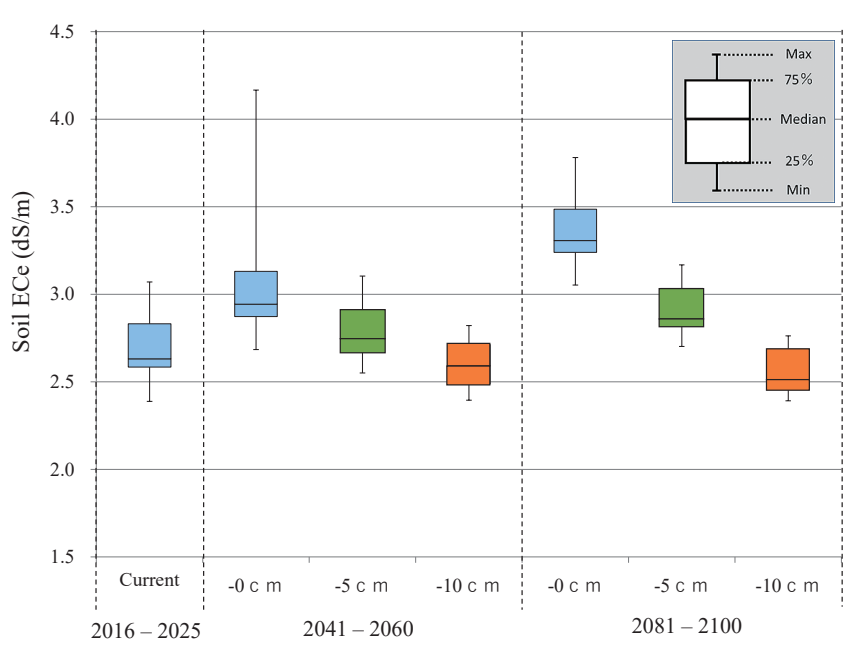

Figure 5. Future changes of soil ECe in rainy season and mitigation effect at different groundwater levels

increased $206 \%$, at a rate of $0.054 \mathrm{dS} / \mathrm{m} /$ year, when the period 2080-2099 was compared to the corresponding baseline salinity during 2004-2015. In Phogat's study, the average rainfall over the period was projected to decline by $13.7 \%$, and the average median ET increased by $5.0 \%$. HajAmor and Bouri (2020) reported that soil ECW in Tunisia increased by $35 \%$, at a rate of $0.082 \mathrm{dS} / \mathrm{m} /$ year up to 2050 . This trend is a consequence of a projected temperature increase of approximately $2^{\circ} \mathrm{C}$ by 2050 , which would certainly increase soil evaporation and reduce soil moisture.

Li et al. (2015) simulated the effects of groundwater control on soil salinity and showed an opportunity for significant reduction in salt accumulation in the root zone. In general, the root zone ECe increases with upward movement of the groundwater table. Therefore, in this study, to understand the impacts of groundwater control, the reductions of $5 \mathrm{~cm}$ and $10 \mathrm{~cm}$ in the groundwater level were evaluated as adaptative countermeasures to climate change. Figure 5 also shows future change of soil ECe in the rainy season at different groundwater levels (GWL). The $-5 \mathrm{~cm}$ GWL case showed that the mitigation of future ECe increase; however, soil ECe still increased at a rate of $0.003 \mathrm{dS} / \mathrm{m} /$ year. Contrastingly, the $-10 \mathrm{~cm}$ GWL case showed a gradual ECe reduction by $-0.002 \mathrm{dS} / \mathrm{m} /$ year until $2081-2100$. The reason why the $-10 \mathrm{~cm}$ case of $2081-2100$ has a smaller ECe than the $-10 \mathrm{~cm}$ case of $2041-2060$ is because the salt amount moving down by leaching becomes larger than it moving up from groundwater by capillary rise. Therefore, a $10 \mathrm{~cm}$ reduction in groundwater level is a target which can mitigate the negative impact of climate change on soil ECe and even improve the soil salinity level by disconnecting the capillary rise of groundwater. One possible approach is partial afforestation. Sahunalu (2003) argued that afforestation is an ideal way to lower groundwater levels and reduce the discharge of salt into lowlands. Moreover, Mukhopadhyay et al. (2021) mentioned that biodrainage is an effective technique, using tree species to reduce the water table by transpiration, primarily in waterlogged areas. For example, Dagar et al. (2016) revealed that Eucalyptus lowered the groundwater table by $38.5 \mathrm{~cm}$ in $1 \mathrm{~m} \times 2 \mathrm{~m}$, and $31.5 \mathrm{~cm}$ in $1 \mathrm{~m} \times 3 \mathrm{~m}$ spacings during the fourth year of plantation compared with no tree plantation. The indirect benefit of this method is the regeneration and amelioration of degraded and unproductive land.

\section{CONCLUSIONS}

In this study, future salt accumulation risks under climate change in northeast Thailand were identified through longterm simulations using HYDRUS-1D. To evaluate the seasonal changes in soil ECe, 15 soil samples were collected every 2 weeks from October 2016 to December 2018, and the ECe, SWC, and soil textures were analyzed. The model parameters of HYDRUS-1D were calibrated and validated by comparison with the observed data. The simulated SMC and ECe were in good correspondence with the observed data in both the calibration and verification periods. Then, using the model, future soil salinity levels were predicted, and the effect of groundwater control was assessed as an adaptative countermeasure to climate change. Without groundwater control, the predicted ECe in rainy season significantly increased by $25.7 \%$, at a rate of $0.01 \mathrm{dS} / \mathrm{m} /$ year until 2081-2100, although the annual increment was lower than in previous studies. However, according to the model, groundwater drainage would be effective in reducing, or reversing, the negative impacts of climate change on soil salinization. In particular, at this study site, a $10 \mathrm{~cm}$ reduction in groundwater level should be a target to mitigate the negative impact of climate change on soil ECe and to improve the soil salinity level. In future studies, an ensemble assessment is appropriate to evaluate the uncertainty of the GCM and climate scenarios. Also, we focused on the seasonal and future change of soil ECe in surface soil. However, vertical profile also should be measured and be evaluated to understand the dynamics of salinity transport for further study.

\section{ACKNOWLEDGMENTS}

This research was supported by JST/JICA, SATREPS, and the MEXT/JSPS Grant-in-Aid for Scientific Research (KAKENHI) no.19H03069 and no.20KK0346.

\section{REFERENCES}

Allen RG, Pereira LS, Raes D, Smith M. 1998. Crop evapotranspiration-guidelines for computing crop water requirements. FAO Irrigation and drainage paper 56. Food and Agriculture Organization, Rome.

Arunin S, Pongwichian P. 2015. Salt-affected soils and management in Thailand. Bulletin of the Society of Sea Water Science, Japan 69: 319-325. DOI: 10.11457/swsj.69.319.

Corwin DL, Scudiero E. 2020. Field-scale apparent soil electrical conductivity. Soil Science Society of America Journal 84: 1405-1441. DOI: 10.2136/methods-soil.2015.0038.

Dagar JC, Lal K, Ram J, Kumar M, Chaudhari SK, Yadav RK, Ahamad S, Singh G, Kaur A. 2016. Eucalyptus geometry in agroforestry on waterlogged saline soils influences plant and soil traits in North-West India. Agriculture, Ecosystems \& Environment 233: 33-42. DOI: 10.1016/j.agee.2016.08.025. 
Dissataporn C, Yacouba K, Mihara M, Yasutomi R. 2002. Effect of groundwater level on salinity content and environmental land classification. Journal of the Japanese Society of Soil Physics 89: 35-42.

Dołęgowska S, Gałuszka A, Migaszewski ZM. 2016. Heterogeneous areas-identification of outliers and calculation of soil sampling uncertainty using the modified RANOVA method. Environmental Monitoring and Assessment 188: 581. DOI: $10.1007 / \mathrm{s} 10661-016-5584-9$.

Food and Agriculture Organization. 2012. Crop yield response to water. FAO Irrigation and drainage paper 66, Food and Agriculture Organization, Rome.

Haj-Amor Z, Bouri S. 2020. Use of HYDRUS-1D-GIS tool for evaluating effects of climate changes on soil salinization and irrigation management. Archives of Agronomy and Soil Science 66: 193-207. DOI: 10.1080/03650340.2019.1608438.

Hassani A, Azapagic A, Shokri N. 2020. Predicting long-term dynamics of soil salinity and sodicity on a global scale. Proceedings of the National Academy of Sciences of the United States of America 117: 33017-33027. DOI: 10.1073/ pnas.2013771117.

Hempel S, Frieler K, Warszawski L, Schewe J, Piontek F. 2013. A trend-preserving bias correction - the ISI-MIP approach. Earth System Dynamics 4: 219-236. DOI: 10.5194/esd-4219-2013.

Kanzari S, Ben Nouna B, Ben Mariem S, Rezig M. 2018. Hydrus-1D model calibration and validation in various field conditions for simulating water flow and salts transport in a semi-arid region of Tunisia. Sustainable Environment Research 28: 350-356. DOI: 10.1016/j.serj.2018.10.001.

Li H, Yi J, Zhang J, Zhao Y, Si B, Lee Hill R, Cui L, Liu X. 2015. Modeling of soil water and salt dynamics and its effects on root water uptake in Heihe arid wetland, Gansu, China. Water 7: 2382-2401. DOI: 10.3390/w7052382.

Merdun H. 2012. Effects of different factors on water flow and solute transport investigated by time domain reflectometry in sandy clay loam field soil. Water, Air, \& Soil Pollution 223: 4905-4923. DOI: 10.1007/s11270-012-1246-x.

Miura K, Subhasaram T. 1990. Soil salinity after deforestation and control by reforestation in Northeast Thailand, tropical agriculture research series. Proceedings of a Symposium on Tropical Agriculture Researches 24: 186-196.

Mukhopadhyay R, Sarkar B, Jat HS, Sharma PC, Bolan NS. 2021.
Soil salinity under climate change: Challenges for sustainable agriculture and food security. Journal of Environmental Management 280: 111736. DOI: 10.1016/j.jenvman.2020. 111736.

Oo AN, Iwai CB, Ngarm BT. 2011. Ecological management in salt-affected area of Northeast Thailand: Monitoring soil quality. International Journal of Environmental and Rural Development 2: 43-48.

Parihar P, Singh S, Singh R, Singh VP, Prasad SM. 2015. Effect of salinity stress on plants and its tolerance strategies: A review. Environmental Science and Pollution Research 22: 4056-4075. DOI: 10.1007/s11356-014-3739-1.

Phogat V, Cox JW, Šimůnek J. 2018. Identifying the future water and salinity risks to irrigated viticulture in the MurrayDarling Basin, South Australia. Agricultural Water Management 201: 107-117. DOI: 10.1016/j.agwat.2018.01.025.

Phontusang P, Katawatin R, Pannangpetch K, Lerdsuwansri R, Kingpaiboon S, Wongpichet K. 2018. Field-scale spatial variability of electrical conductivity of the inland, saltaffected soils of Northeast Thailand. Walailak Journal of Science and Technology 15: 341-355. DOI: 10.48048/ wjst.2018.3474.

Ramos TB, Šimůnek J, Gonçalves MC, Martins JC, Prazeres A, Castanheira NL, Pereira LS. 2011. Field evaluation of a multicomponent solute transport model in soils irrigated with saline waters. Journal of Hydrology 407: 129-144. DOI: 10.1016/j.jhydrol.2011.07.016.

Roengsak K, Somsak S. 2012. Mapping soil salinity and soil erosion in Thailand with emphasis on computer-assisted techniques. Pedologist 55: 343-354. DOI: 10.18920/pedologist. $55.3 \_343$.

Sahunalu P. 2003. Rehabilitation of salt affected lands in Northeast Thailand. Tropics 13: 39-51. DOI: 10.3759/tropics. 13.39 .

Simunek J, van Genuchten MT, Sejna M. 2016. Recent developments and applications of the HYDRUS computer software packages. Vadose Zone Journal 15: 1-25. DOI: 10.2136/ vzj2016.04.0033.

Yavitt JB, Harms KE, Garcia MN, Wright SJ, He F, Mirabello MJ. 2009. Spatial heterogeneity of soil chemical properties in a lowland tropical moist forest, Panama. Soil Research 47: 674-687. DOI: 10.1071/SR08258. 